\title{
Sudden death associated with bleeding into digestive system of finishing pigs - a review
}

\author{
Jaroslav Novotný ${ }^{1}$, Peter Reichel ${ }^{1}$, Petronela Kyzeková1, René Mandelík ${ }^{2}$ \\ University of Veterinary Medicine and Pharmacy, ${ }^{1}$ University Veterinary Hospital, Clinic of Swine, \\ ${ }^{2}$ Department of Epizootiology, Parasitology and Protection of One Health, Košice, Slovakia
}

Received December 4, 2020

Accepted February 24, 2021

\begin{abstract}
Sudden deaths of finishing pigs in modern pig herds cause economic losses and therefore draw constant attention worldwide. In the case of peracute mortality associated with gastrointestinal bleeding, pigs usually die during a short period without clinical manifestations. Necropsy can detect bleeding into various parts of the digestive system. Determining the exact aetiology of the sudden death can be difficult in many cases. Diseases and conditions such as gastric ulcers, abdominal torsion, haemorrhagic bowel syndrome and infectious diseases should be taken into account in the differential diagnosis. Because some of these diseases still have an unclear aetiology and pathogenesis, the aim of our work was to provide a summary of existing knowledge as well as to describe related pathognomonic pathological changes.
\end{abstract}

Finisher, swine, gastrointestinal bleeding, peracute mortality

The profitability and productivity of pig finishing units is affected by many factors, including nutrition, housing conditions and mortality of fattening pigs. Moreover, the mortality rate, average daily weight gain, and feed conversion ratio are important indices used to measure performance in grow-finish pigs (Brumm 1995; Whittemore 1998). It is clear that financial losses due to mortality vary greatly depending on whether pigs die at the beginning or at the end of the finishing period (Maes et al. 2001).

Finishing pigs are pigs close to the market weight and can die due to a variety of causes, including infectious diseases causing viraemia, septicaemia, and toxaemia, as well as diseases causing inflammation and changes in the cardiovascular system (endocarditis, mulberry heart disease, porcine stress syndrome), pathology in the urinary and also digestive tract (Leiting 2011). At present, a major threat to pig farming is the African swine fever which can also cause sudden death (Gogin et al. 2013; Yoon et al. 2020).

Sudden death or peracute mortality associated with haemorrhage into the digestive system of pigs is characterized by the death of a previously asymptomatic animal, mostly in a good condition, with a good appetite, and without presence of diarrhoea (Friendship 2004; Pejsak 2007; Novotný et al. 2016). It is also important to note whether the sudden death occurred with or without the presence of fever. In the case of fever, the involvement of infectious pathogens must be considered (Fedorka-Cray et al. 2000).

The objective of this paper was to review the diseases leading to sudden deaths of finishing pigs manifested by haemorrhage into the digestive system.

\section{Gastric ulceration}

Gastric ulcers are common in pigs kept under modern husbandry conditions and may cause clinical disease or death when haemorrhage or perforation occurs (Friendship 2004, 2006; Omoto sho et al. 2016). Stomach erosive lesions together with pre-ulcerative parakeratosis lesions belong to the most common postmortem findings in the stomach of

Address for correspondence:

MVDr. Jaroslav Novotný, PhD.

University Veterinary Hospital, Clinic of Swine

University of Veterinary Medicine and Pharmacy

Košice, Komenského 73, 04181, Slovakia
Phone: +421915986697

E-mail: jaroslav.novotný@uvlf.sk

http://actavet.vfu.cz/ 
pigs at slaughter (Melnichouk 2002; Monteiro 2011). The prevalence of this disease varies a lot depending on the husbandry and feeding regimes (Berrios et al. 2019). The prevalence of lesions in the literature is reported to be about 32-65\% (Christensen and Cullinane 1990; Straw et al. 1992). Some sources even report a prevalence of up to $93 \%$ (Haesebrouck et al. 2009).

The gastric mucosa of pigs is compartmentalized into four regions that differ in appearance and structure: esophageal, fundic, cardiac and pyloric. The only the esophageal region of stomach has non-glandular mucosa. It is located at the site of the esophageal entry into the stomach and is actually a continuation of the esophageal mucosa (Gandarillas and Bas 2009). Gastric ulcers are almost exclusively restricted in this non-glandular region (Kopinski and McKenzie 2007; De Witte et al. 2017). Less frequently and due to other causes such as bacterial septicaemia or an outbreak of pneumonia, ulcers can also occur in the mucous and acid-secreting regions (Monteiro 2011).

Blood loss is often so severe and acute that the pig is found dead before clinical signs have been detected (Friendship 2004). Sudden death usually involves only a small number of pigs in a grower-finisher barn, but higher numbers can occur sporadically and are usually associated with a triggering event such as feed disruption (Melnichouk 2002). Mortality due to bleeding from deep, erosive lesions may reach $1 \%$ or higher, with culling losses of 3\% to 5\% in such herds (Nielsen 1995). Similarly, other studies estimate approximate annual mortality attributable to gastroesophageal ulcers from $0.5 \%$ to $0.75 \%$ (Deen 1993 ; Melnichouk 2002).

The aetiology has not been fully understood but is likely to be multifactorial. The pig helicobacter, Helicobacter suis, is present in the stomach and is capable of causing chronic gastritis and ulceration (Hellemans et al. 2007; De Bruyne et al. 2012; De Witte et al. 2017). Other bacteria can ferment carbohydrate, producing organic acids and predisposing the pars oesophagea to ulceration. Pneumonia caused by infectious pathogens and infestation by the stomach worm, Hyostrongylus rubidis, may predispose to ulceration of the glandular portion of the stomach (Dionissopoulos et al. 2001; Berrios et al. 2019). Although in some studies with mild Hyostrongylus infestation, neither ulceration nor haemorrhage was recorded in the gastric mucosa of the fundic region (Sarashina and Taniyama 1986). Nutrition and management are also important in the maintenance and exacerbation of the lesions, especially finely ground or pelleted feeds may be involved (Wondra et al. 1995; Ayles et al. 1996). Stresses such as transport, starvation, interruption of feed intake, mixing and overcrowding increase the incidence of gastric ulceration in pigs (Lawrence et al. 1998). Hormonal changes have been also hypothesized to be involved (Bubenik et al. 1998).

\section{Pathogenesis}

Ulcers can develop quickly within 12 h (Davies et al. 1994). Generally, an imbalance between gastric acid secretions, changes in mucous composition and gastric mucosa protection is necessary for the development of ulcers in pigs. When the gastric mucosa is damaged, hydrochloric acid and pepsin can easily further damage the submucosa of the stomach. The particle size and physical form of the feed influences the pepsin and acid secretion in the stomach also by high fermentable carbohydrates. The ulcerative process may progress from a thickening of the mucosa at the beginning to erosions, ulceration, and haemorrhage to a perforated ulcer in the stomach (Friend ship 2004; Berrios et al. 2019).

\section{Pathological findings}

Pigs that have died because of haemorrhage from ulcers appear notably pale but generally in a good body condition and without bloating. The stomach usually does not contain feed. It is often distended with clotted blood or blood mixed with ingesta and the intestines are 
filled with blood or melenic content - brown digested blood (Schwartz 2002; Friendship 2004). Usually, macroscopic findings at necropsy are sufficient for diagnosis. Because a gastric ulcer death may be secondary to another clinical problem (Dionissopoulos et al. 2001), it is important to note other diseases present in the animal at the time of necropsy (Friendship 2004).

Stomachs from slaughtered pigs can be also analysed for the presence of macroscopic lesions suggesting gastric ulcer. Scores from 0 to 4 were attributed to the stomachs depending on the extent of the lesions, namely: score 0 - normal stomach; score 1 - stomach showing parakeratosis; score 2 - stomach showing active or chronic ulcer covering less than $33 \%$ of the pars oesophagea; score 3 - stomach showing active or chronic ulcer covering from 33 to $66 \%$ of the pars oesophagea; score 4 - stomach showing active or chronic ulcer covering more than $66 \%$ of the pars oesophagea (Kopinski and Mckenzie 2007; Prazeres et al.2017).

\section{Torsion of abdominal organs}

These acute abdominal accidents mainly involve torsion of the stomach and intestines. Death can be sporadic or in infrequent outbreaks (White 2002). Long-loined pigs may be more likely to develop mesenteric torsion than shorter pigs (Straw et al. 2002; Harris 2013).

\section{Gastric torsion}

Gastric torsion is a rare condition in which sudden death follows feeding. The stomach twists around the longitudinal axis of the digestive tract, also known as volvulus. This condition most often occurs following a once-daily feeding and can be prevented by feeding twice daily.

The possibility of gastric torsion is related to the capacity of the stomach and its placement. The stomach belongs to the most dilated part of the digestive tract, and its capacity ranges from approximately 3.51 in slaughter pigs to 51 in adults. Under pressure, the capacity increases to 8 and 121 for slaughter and adult pigs, respectively (Lærke and Hedemann 2012). The pig stomach is not firmly fixed in its position. Its long axis is directed transversely. The empty stomach is located in the diaphragm dome, surrounded by liver lobes. However, the distended stomach may touch the right abdominal wall at the level of rib 13, just caudally from the liver. A grossly distended stomach can touch the left rib arch, it can push away the jejunal loops, coming into contact with the large intestine (Popesko et al. 1992).

\section{Aetiology}

Adult animals that are occasionally susceptible to torsion of the intestine, are more likely to suffer gastric dilation and torsion, which is equally fatal (White 2002). Deaths are usually sporadic although they can be of significance where, for example, fresh whey is being fed and bloating occurs. The predisposition is overeating with liquid feed. Prolonged over-excitement at feeding may also predispose.

\section{Pathogenesis}

It is believed that rapid ingestion of feed possibly coupled with fermentation of feed mass leads to dilatation and, in conditions of excitement, to torsion. In addition, gorging and fast intake of feed can lead to possible swallowing of large amounts of air which triggers the process of gastric dilatation (White 2002). Another explanation of the stomach dilatation and volvulus may be the dysfunction of the sphincter between the oesophagus and the stomach and the obstruction of the outflow through the pylorus caused by gastric 
ulcers. This has been well documented in dogs (Parton et al. 2006). The pylorus, which is usually located ventrally and directed to the right of the body of the stomach, is twisted cranially or to the left of the midline because of gas accumulation. If the volvulus is greater than $180^{\circ}$, the oesophagus is closed off, thereby preventing the animal from relieving the condition by belching or vomiting. Gastric torsion and gas distension result in low blood pressure, decreased return of blood to the heart, ischaemia of the stomach, and shock. Without circulation, the stomach tissue discolours and dies. The lungs are congested as a result of the pressure on the diaphragm. Death is usually due to this pressure build-up causing either suffocation or heart failure. Mortality can also result from rupture of the spleen and loss of blood into the abdominal cavity (White 2002).

\section{Pathological findings}

It often affects the best pigs of the group that are found dead. Pigs that have died from torsion may have distended abdomens. Paleness is not a regular feature (White 2002). Torsion of the spleen and sometimes associated splenic rupture may also be present. Most pigs with gastric torsion had large amounts of gastric content composed of fluid and partly digested food (Filipov 1983; Morin et al. 1984).

\section{Intestinal torsion}

Intestinal torsion is one of the most common causes of sudden death in growing pigs between 25 and $100 \mathrm{~kg}$ (White 2002). Also known as intestinal volvulus or twisted gut.

The intestinal tract of the pig is suspended within the abdominal cavity below the spine. The small intestine of fully developed pigs is $16-21 \mathrm{~m}$ long and has a capacity of more than 20 1. The large intestine reaches a length of up to $5 \mathrm{~m}$ with a capacity of up to about 101 (Lærke and Hedemann 2012). This mass of intestinal loops is attached to vertebras by the mesentery only in a short section, which can lead to possible partial or even complete torsion of intestines.

\section{Aetiology}

It is caused by consumption of large amounts of feed in a very short time. An important provoking factor is over-feeding and abnormal fermentation of the contents of both the small and large intestine result in gas formation, increased pressure and torsion (Ruckebusch and Bueno 1976). Highly fermentable rations containing whey or other carbohydrate-rich liquid may reach the caecum, ferment, and cause torsion of the whole large intestinal mass around its root in finishers. Other factors include improper feed supply, especially when feeding is interrupted, inadequate feeder space and overstocking associated with gorging of feed, mainly in the last phase of finishing period. In addition, a very important factor is colitis, which is associated with the multiplication of bacteria in the hindgut, leading to greater feed fermentation and gas production (White 2002; Martineau et al. 2008; Thomson and Friendship 2019).

\section{Pathogenesis}

Intestinal instability is increased by excessive gas production. Sudden movements then allow the gut loops to rotate and cause a constrictive twist. Torsion of the long axis of mesentery cuts off the blood supply to the gut and causes rapid death (White 2002; Thomson and Friendship 2019).

\section{Pathological findings}

In most cases, pigs are found dead, pale, and bloated (White 2002). Intestines that have a complete obstruction of the blood flow are black and necrotic; partial volvulus is characterised by markedly red colour (Schwartz 2002). Rotation is usually counter- 
clockwise when viewed from the ventrocaudal aspect of animal (Thom son and Friend ship 2019). The normal position of the colon and caecum is on the left side with the apex of the cecum pointing caudally. The caecum and colon may be rotated to the right when there is partial or complete volvulus of the small and/or large intestine (Schwartz 2002). The mesenteric root should be palpated before opening the entire abdomen, with the pig in a position on the back. Torsion is palpable as a knot depending on how much of mesentery is twisted. However, only partial rotation is difficult to demonstrate at necropsy, which makes diagnosis more challenging. Mesenteric torsion obstructs the venous outflow of blood which causes blood to pool and stagnate in the intestine (Schwartz 2002; Haris 2013). Occasionally, intestinal torsion is unwinding due to transport or postmortal repositioning of the gut. However, the red discoloration of the intestine is still visible even if the volvulus has been repositioned. Similarly, rough handling of the carcase during transport can result in apparent torsions, but these can be distinguished by the absence of the intense red colour from the twisted organ (Häni et al. 1993; Straw et al. 2002; Grahofer et al. 2017).

\section{Haemorrhagic bowel syndrome}

It is also called intestinal haemorrhage syndrome, porcine intestinal distension syndrome, bloody or red gut (Martineau et al. 2008; Thomson and Friendship 2019). Haemorrhagic bowel syndrome (HBS) is a sporadically occurring disorder in fattening pigs, characterized by sudden death in combination with severe abdominal distension and intense red colouration of the intestine (Labuscagne et al. 2012; Grahofer et al. 2017). Haemorrhagic bowel syndrome primarily affects rapidly growing pigs between 4 and 6 months of age of 70 to $120 \mathrm{~kg}$ (Straw et al. 2002; Hollis 2006; Harris 2013). Production systems attribute mortality rates of $0.1-7 \%$ to HBS in the grow-finish phase (Schwartz 2002).

\section{Aetiology}

Exact aetiology and pathogenesis of HBS is still unclear (Holis 2006; Martineau et al. 2008). However, several specific risk factors associated with the deaths have been defined (Schwartz 2002). Some authors allege that HBS is the result of intestinal volvulus; others declare that this condition may be associated with infectious pathogens or a combination of non-infectious and infectious causes (Häni et al. 1993; Schwartz 2002; Straw et al. 2002; Labuscagne et al. 2012; Novotný et al. 2016; Grahofer et al. 2017). Highly fermentable rations such as liquid feed or rations including whey have been most often associated with clinical cases of HBS. It is also hypothesized that deaths in the absence of intestinal torsion may be caused by excessive intra-abdominal pressure that reaches the same levels of pigs with "whey bloat" (Thoms on et al. 2007). The overgrowth and (or) alteration of bacteria such as Clostridium or E. coli in the digestive tract with consequent over-production of toxic substances should be considered (Labuscagne at al. 2012; Novotný et al. 2016; Grahofer et al. 2017). This has been well documented in ruminants, where various risk factors contribute to the overgrowth of normal intestinal flora, with sequelae such as acidosis, endotoxaemia, enterotoxaemia, and death (Dennison et al. 2002). In addition, chronic dysbacteriosis of the intestinal tract due to the non-justified routine use of antimicrobials may also predispose (Grahofer et al. 2017). Of course, animal husbandry aspects are also very important, such as nutrition, management, feeding regime, nutritional hygiene, housing density, and optimal feeding space (Holis 2006).

\section{Pathogenesis}

Excessive intra-abdominal pressure in "whey bloat" pigs cause obstruction of the mesenteric veins and obstruction of the venous return (Gudmundsson et al. 2001). 
Clostridium spp., E. coli or other intestinal bacterial overgrowth with the production of exotoxins, enterotoxins or endotoxins may have a localized effect and can perhaps create shock-like conditions in the intestine (Schwartz 2002). Antimicrobials introduced to the feed provoke a selective pressure that may lead to long lasting changes in livestock commensal microorganisms, helping the pathogens to multiply in the gastrointestinal tract (Götz et al. 1996; Salyers and Abile-Cuevas 1997; Grahofer et al. 2017).

\section{Pathological findings}

Recently dead animals have a typical marked pallor of the skin and pronounced distension of the abdomen (Straw et al. 2002). An indication of peracute mortality is the stomach filled with fresh feed. The intestines have a similar appearance to cases of intestinal torsion, but no obvious displacement of the intestines or mesenteric torsion are detected at necropsy (Thomson and Friendship 2019). Transmural congestion affecting the serosa, intestinal wall, and mucosa is observed, but microscopic lesions are similar and not specific for either volvulus or HBS (Schwartz 2002). The small intestine is thin-walled at necropsy and filled with either clotted or unclotted blood (Hollis 2006; Harris 2013). The mesenteric vasculature is extremely engorged due to the obstruction to the venous return. The large intestine may contain tarry faecal material, but lesions of gastric and intestinal mucosa, suggestive of gastric ulceration, proliferative haemorrhagic enteropathy, swine dysentery or salmonellosis are absent (Hollis 2006). Sometimes the large intestine is without pathological findings, containing regular ingesta. A sharp demarcation is seen between the normally coloured part of the intestine and the red affected intestine (Grahofer et al. 2017).

\section{Diseases associated with infectious causes}

Not all pigs that die suddenly and are pale have stomach or intestinal accidents. Differential diagnosis includes other causes of sudden death, which, in contrast to previously mentioned diseases, are often associated with bloody diarrhoea. These include porcine proliferative enteritis, swine dysentery, and salmonellosis.

\section{Porcine proliferative enteropathy}

An acute form of porcine proliferative enteropathy known as proliferative haemorrhagic enteropathy (PHE) can in some cases cause sudden death and acute haemorrhagic diarrhoea in replacement animals and finishing pigs close to the market age (Guedes 2004).

Clinical presentation is mainly characterized by high mortality associated with anaemia and haemorrhagic diarrhoea (Pascua et al. 2015). However, some animals die without faecal abnormality and show only marked pallor (Vannucci et al. 2019). Globally, it is estimated that $96 \%$ of farm sites are infected, with approximately $30 \%$ of weaner-tofinisher pigs having lesions of variable severity and duration (Stege et al. 2000; McOrist et al. 2003).

\section{Aetiology}

The aetiologic agent of PHE in swine is the obligate intracellular Gram-negative bacterium Lawsonia intracellularis (Lawson et al. 1993; Gebhart et al. 1993). An explosive outbreak of PHE occurs mainly in the naive pig population. Various organizational activities in farms such as transportation of pigs, changes in the feeding regimen or the diet, sudden temperature variations, overpopulation, impaired hygienic or immune status as well as a genetic predisposition could influence the appearance, the development and severity of porcine proliferative enteropathy (Bona and Bilkei 2003; Hagen and Bilkei 2003). 
The pathogenesis of this more acute lesion is not well characterized. However, haemorrhage occurs concurrently with the widespread degeneration and desquamation of many epithelial cells and leakage from the capillary bed (Vannucci and Gebhart 2014; Vannucci et al. 2019).

\section{Pathological findings}

Based on morphological properties, four forms of the disease are recognised in pigs: porcine intestinal adenomatosis (PIA), necrotic enteritis (NE), regional ileitis (RI) and proliferative haemorrhagic enteropathy (PHE). In the more recent literature, the terms acute (PHE) and chronic (PIA or NE) forms are preferred (Bronsvoort et al. 2001; Jacobson et al. 2010). The intestine is dilated and the wall is thickened by serosal oedema and mucosal proliferation. Proliferative haemorrhagic enteropathy is marked by severe bleeding into the lumen of the intestine, but with underlying cell proliferation typical of proliferative enteropathy. The lumen of the ileum and proximal colon usually contain one or more formed blood clots combined with fibrinonecrotic debris. The rectum may contain black tarry faeces of mixed blood and digesta (McOrist et al. 2006; Vannucci et al. 2019).

\section{Swine dysentery}

Swine dysentery (SD) is a severe enteric disease in grower-finisher pigs, characterized by bloody to mucoid diarrhoea associated with reduced growth performance and variable mortality (Burrough 2017). Occasionally, pigs are peracutely affected and die within a few hours to days as a result of the endotoxin release (Hampson and Burrough 2019).

\section{Aetiology}

Swine dysentery is associated with strongly haemolytic, Gram-negative anaerobic Brachyspira species. Except $B$. hyodysenteriae, the classical agent of SD, two other strongly beta-haemolytic spp. (B. hampsonii and B. suanatina) are also agents of SD in some parts of the world (Mushtaq et al. 2015; Hampson and Burrough 2019). Outbreaks of SD are often associated with various stressors, including moving to new pens, mixing with different animals, weighing, change in feed, over-crowding, and/or extreme changes in ambient temperature. It also coincides with removal of antimicrobials used to control respiratory and enteric diseases (Hampson and Burrough 2019). Factors affecting disease transmission include environmental survival of the pathogen, animal husbandry factors (production system, production stage, farm management), role of vectors, diet influence and interaction of the microorganism with gut microbiota (Backhans et al 2010; Alvarez-Ordóñez et al. 2013).

The pathogenesis of SD is incompletely understood. Individual animal susceptibility to development of SD varies and is, in part, due to differences in the colonic microbiota (Hampson and Burrough 2019). The spirochetes must survive the acidic environment of the stomach and pass through the small intestine until ultimately reaching, colonizing, and proliferating in the caecum and colon (Burrough 2017). Brachyspira hyodysenteriae colonizes the mucus layer and is often found deep within crypts (Milner and Sellwood 1994; Kennedy and Yancey 1996). Colonization within the mucus layer and crypts helps further protect the spirochetes from potential oxygen toxicity at the surface, and flagellar function is important in mucus penetration (Burrough 2017). The mechanisms of tissue destruction in SD are not fully understood. However, it can be associated with disorganization of the mucin layer and its structure (Quintana-Hayashi et al. 2015), which may allow improved access of B. hyodysenteriae to the underlying epithelium. The haemolysin(s) may then cause local damage, resulting in epithelial sloughing. Subsequent 
mucosal and submucosal invasion by secondary bacteria and the protozoan Balantidium coli may contribute to lesion formation (Hampson and Burrough 2019).

\section{Pathological findings}

Lesions are characterized by haemorrhage, necrosis, and increased mucin secretions (Wilberts et al. 2014; Quintana-Hayashi et al. 2015), and are limited to all or part of the caecum through the descending colon with the spiral colon being most consistently affected in acute SD (Wilberts et al. 2014). The small intestine remains clinically unaffected (Stanton 2006).

\section{Salmonellosis}

In terms of sudden deaths, the most important is Salmonella enterica subsp. enterica serovar Choleraesuis that causes a generalized, life-threatening septicaemia with lesions in various organs (Griffith et al. 2019). Sudden death without forewarning signs occurs mainly in pigs in the acute phase of septicaemia. The first evidence of disease are dead pigs with cyanotic extremities and abdomens. In most outbreaks, mortality is high, and morbidity is variable but generally less than $10 \%$ (Wilcock and Sch wartz 1992; Griffith et al. 2019; Zhitnitskiy 2020). Diarrhoea is normally not a feature of $S$. Choleraesuis infection until the third or fourth day of disease, when watery yellow faeces may be seen (Fedorka-Cray et al. 2000).

\section{Aetiology}

Host adapted $S$. Choleraesuis and non-host adapted $S$. enterica serotype Typhimurium are two of the most frequent isolated serovars recovered from clinically diseased swine (Loynachan et al. 2004). Septicaemic $S$. Choleraesuis typically affects growing pigs less than 5 months old. Intestinal salmonellosis caused by Salmonella Typhimurium and antigenically similar $S$. enterica serotype I 1,4,[5],12:i:- are also common in pigs (Moreno Swift et al. 2009). Unlike $S$. Choleraesuis, these salmonellas cause enterotyphlocolitis with lower mortality that occurs only after several days of diarrhoea, presumably as the result of hypokalaemia and dehydration (Griffith et al. 2019). Salmonella Choleraesuis outbreaks are frequently associated with "stress" factors (Wilcock 1981) that have already been mentioned in previous diseases.

\section{Pathogenesis}

Salmonella Choleraesuis is host-adapted to pigs meaning that infection is limited $99 \%$ exclusively to pigs (Uzzau et al. 2000). Salmonella Choleraesuis is transmitted by direct contact and by faeces or faeces-contaminated materials from clinically infected or carrier pigs. Feed and other species of animals are not a source of infection. Oral infection of pigs with $S$. Choleraesuis leads to colonization of palatine tonsil (Gray et al. 1995) and lymphoid tissues of intestine. The organism can survive within macrophages and neutrophils which serve as vehicles for Salmonella dissemination (Gray et al. 1996). Tissue localizations of infection then occur, the most common being liver (hepatitis), spleen (splenomegally), lymph nodes, lung (pneumonia), brain (encephalitis) and joints (synovitis). There, the organism destroys local tissues, causes inflammation, and persists (Schwartz 1991).

\section{Pathological findings}

Cyanosis of the skin, especially on the ears, feet, tail and abdomen, is commonly found on pigs that died unexpectedly. Gross lesions include swollen mesenteric lymph nodes, splenomegaly, hepatomegaly, and lung congestion. Random white foci of necrosis are often observed on the liver (Reed et al. 1986; Wilcock and Schwartz 1992), leading 
to varying degrees of icterus severity. In pigs that have displayed coughing, typical lesions associated with bacterial pneumonia such as consolidation of the cranioventral lobes can be seen (Turk et al. 1992; Zhitnitskiy 2020). Pigs dying of acute septicaemia generally have no lesions in the intestine (Schwartz 1991). When pigs have been sick for several days and show signs of diarrhoea, intestinal lesions similar to the ones seen with $S$. typhimurium infections are observed: pseudomembranes on the ileum and button ulcers in the colon (Zhitnitskiy 2020).

\section{Conclusion}

Peracute mortality is associated with the death of pigs within a few hours or at night, which limits the performance of a clinical examination. Therefore, postmortem examination is the standard primary method of diagnosis. If gastrointestinal bleeding is detected, it is important to focus on the most common causes as outlined in this article. Before a detailed examination of individual parts of the digestive system, it is always necessary to evaluate the possible torsion of the abdominal organs by palpation of the mesenteric root. Final diagnosis is then made by excluding diseases that are not related to the occurrence of the identified lesions. If necessary, additional laboratory tests are used. Study of the literature has shown that the most questionable aetiology and pathogenesis is for the haemorrhagic bowel syndrome where the various causes of the onset and development of this disorder are taken into account. In an effort to minimize losses and manage outbreaks of sudden finisher mortality, it is necessary to implement measures in relation to nutrition, housing, environment and risk factors. Moreover, the improvement on-farm hygiene measures and stimulation of the immune status of animals as well as implementation of management practices that emphasize all-in/all-out production play an important role in the reduction of infectious pathogens.

\section{Acknowledgements}

This publication is the result of the project implementation: "Open scientific community for modern interdisciplinary research in medicine (OPENMED)”, ITMS2014+: 313011V455 supported by the Operational Programme Integrated Infrastructure, funded by the ERDF.

\section{References}

Alvarez-Ordóñez A, Martínez-Lobo FJ, Arguello H, Carvajal A, Rubio P 2013: Swine dysentery: aetiology, pathogenicity, determinants of transmission and the fight against the disease. Int $\mathrm{J}$ Environ Res Public Health 10: 1927-1947

Ayles HL, Friendship RM, Ball RO 1996: Effect of dietary particle size on gastric ulcers, assessed by endoscopic examination, and relationship between ulcer severity and growth performance of individually fed pigs. Swine Health Prod 4: 211-216

Backhans A, Johansson K, Fellström C 2010: Phenotypic and molecular characterization of Brachyspira spp. isolated from wild rodents. Environ Microbiol Rep 2: 720-727

Berrios R, Skaarup Jensen S, Van Lankveld A 2019: Gastric ulcers in swine - a serious welfare and health problem in pig production. Available at https://danbred.com/en/gastric-ulcers/

Bona B, Bilkei G 2003: The effect of outdoor production on the seroprevalence of Lawsonia intracellularis in growing-finishing pigs in a large pig production unit infected with endemic porcine proliferative enteropathy. Dtsch Tierarztl Wochenschr 110: 73-75

Bronsvoort M, Norby B, Bane DP, Gardner IA 2001: Management factors associated with seropositivity to Lawsonia intracellularis in US swine herds. J Swine Health Prod 9: 285-290

Brumm M 1995: Maximizing profit from the growing-finishing phase. Proc AD Leman Swine Conf, St Paul, Minnesota, USA, pp. 137-142

Bubenik GA, Ayles HL, Friendship RM, Brown GM, Ball RO 1998: Relationship between melatonin levels in plasma and gastrointestinal tissues and the incidence and severity of gastric ulcers in pigs. J Pineal Res 24: $62-66$

Burrough ER 2017: Swine dysentery: etiopathogenesis and diagnosis of a reemerging disease. Vet Pathol 54: 22-31 
Christensen N, Cullinane L 1990: Monitoring the health of New Zealand abattoirs. New Zealand Vet J 38: 136-141

Davies PR, Grass JJ, Marsh WE, Bahnson PB, Dial GD 1994: Time of slaughter affects prevalence of lesions of the pars oesophagea of pigs. $13^{\text {th }}$ Proc Int Pig Vet Cong, Bangkok, Thailand, p. 471

De Bruyne E, Flahou B, Chiers K, Meyns T, Kumar S, Vermoote M, Pasmans F, Millet S, Dewulf J, Haesebrouck F, Ducatelle R 2012: An experimental Helicobacter suis infection causes gastritis and reduced daily weight gain in pigs. Vet Microbiol 160: 449-454

De Witte C, Devriendt B, Flahou B, Bosschem I, Ducatelle R, Smet A, Haesebrouck F 2017: Helicobacter suis induces changes in gastric inflammation and acid secretion markers in pigs of different ages. Vet Res 48: 34

Deen J 1993: The problem of gastroesophageal ulcers: a field description. Proc Leman Swine Conf, College of Veterinary Medicine, University of Minnesota, pp. 137-138

Dennison AC, VanMetre DC, Callan RJ, Dinsmore P, Mason GL, Ellis RP 2002: Hemorrhagic bowel syndrome of adult dairy cattle: 22 cases (1997 - 2000). J Am Vet Med Assoc 221: 686-689

Dionissopoulos L, deLange CFM, Dewey CE, MacInnes JI, Friendship RM 2001: Effect of health management strategy during rearing on grower-finisher pig performance and selected indicators of immune system stimulation. Can J Anim Sci 81:179-187

Fedorka-Cray PJ, Gray JT, Wray C 2000: Salmonella infections in pigs. In: Wray C, Wray A: Salmonella in Domestic Animals, CABI publishing, Oxon, Great Britain pp. 191-209

Filipov MM 2006: Gastric torsion in gestating sows. Proc Am Assoc Swine Pract, Kansas City, Missouri, USA, p. 173

Friendship RM 2004: Gastric ulceration in swine. J Swine Health Prod 12: 34-35

Friendship RM 2006: Gastric ulcers. In: Straw BE, Zimmerman J, D’Allaire S, Taylor DJ (Eds): Diseases of Swine. $9^{\text {th }}$ edn. Blackwell Publishing, Ames, Iowa, USA, pp. 891-899

Gandarillas M, Bas F 2009: The domestic pig (Sus scrofa domestica) as a model for evaluating nutritional and metabolic consequences of bariatric surgery practiced on morbid obese humans. Cien Inv Agr 36: 163-176

Gebhart CJ, Barns SM, McOrist S, Lin GF, Lawson GHK 1993: Ileal symbiont intracellularis, an obligate bacterium of porcine intestine showing a relationship to Desulfuvibrio species. Int J Syst Bacteriol 43: 533-538

Gogin A, Gerasimov V, Malogolovkin A, Kolbasov D 2013: African swine fever in the North Caucasus region and the Russian Federation in years 2007-2012. Virus Res 173: 198-203

Götz A, Pukall R, Smit E, Tietze E, Prager R, Tschäpe H, van Elsas JD, Smalla K 1996: Detection and characterization of broad-host-range plasmids in environmental bacteria by PCR. Appl Environ Microbiol 62: $2621-2628$

Grahofer A, Gurtner C, Nathues H 2017: Haemorrhagic bowel syndrome in fattening pigs. Porc Health Manag 3: 27

Gray JT, Fedorka-Cray PJ, Stabel TJ, Kramer TT 1996: Natural transmission of Salmonella choleraesuis in swine. Appl Environ Microbiol 62: 141-146

Gray JT, Fedorka-Cray PJ, Stabel TJ 1995: Influence of inoculation route on the carrier state of Salmonella choleraesuis in swine. Vet Microbiol 47: 43-59

Griffith R W, Carlson SA, Krull AC 2019: Salmonellosis. In: Zimmerman JJ, Karriker LA, Ramirez A, Schwartz KJ, Stevenson GW, Zhang J (Eds): Diseases of Swine. $11^{\text {th }}$ edn. John Wiley \& Sons, Inc., Ames, IA, USA, pp. 749-766

Gudmundsson FF, Gislason HG, Dicko A, Horn A, Viste A, Grong K 2001: Effects of prolonged increased intra-abdominal pressure on gastrointestinal blood flow in pigs. Surg Endosc 15: 854-860

Guedes R 2004: Update on epidemiology and diagnosis of porcine proliferative enteropathy. J Swine Health Prod 12: $134-138$

Haesebrouck F, Pasmans F, Flahou B, Chiers K, Baele M, Meyns T, Decostere A, Ducatelle R 2009: Gastric helicobacters in domestic animals and nonhuman primates and their significance for human health. Clin Microbiol Rev 22: 202-223

Hagen B, Bilkei G 2003: Seroprevalence of Lawsonia intracellularis in large pig production units. Acta Vet Hung 51: $65-170$

Hampson DJ, Burrough ER 2019: Swine dysentery and brachyspiral colitis. In: Zimmerman JJ, Karriker LA, Ramirez A, Schwartz KJ, Stevenson GW (Eds): Diseases of Swine. 11 $1^{\text {th }}$ edn. Wiley-Blackwell, Ames, IA, USA, pp. 951-970

Häni H, Zimmermann W, Huber A, Schmidt J 1993: Das "Hämorrhagische Intestinalsyndrom" (HIS) des Schweines: Klinische, pathologisch-anatomische und ätiopathogenetische Aspekte. Schweiz Arch Tierheilk 135: $117-124$

Harris DLH 2013: Hemorrhagic Bowel Syndrome in Pigs. https:/www.msdvetmanual.com/digestive-system/ intestinal-diseases-in pigs/hemorrhagic-bowel-syndrome-in-pigs

Hellemans A, Chiers K, Decostere A, De Bock M, Haesebrouck F, Ducatelle R 2007: Experimental infection of pigs with "Candidatus Helicobacter suis". Vet Res Commun 31: 385-395

Hollis WL 2006: Will nutrition and management stop hemorrhagic bowel syndrome? A veterinarian's perspective. Midwest Swine Nutrition Conference, Indianapolis, Indiana, USA, pp. 38-41

Jacobson M, Fellström C, Jensen-Waern M 2010: Porcine proliferative enteropathy: An important disease with questions remaining to be solved. Vet J 184: 264-268 
Kennedy MJ, Yancey RJ Jr 1996: Motility and chemotaxis in Serpulina hyodysenteriae. Vet Microbiol 49: 21-30

Kopinski J, Mckenzie R 2007: Oesophagogastric ulceration in pigs: A visual morphological scoring guide. Aust Vet J 85: 356-361

Labuscagne A, Spencer BT, Picard JA, Williams MC 2012: An investigation to determine the cause of haemorrhagic enteritis in commercial pig grower units in the northern parts of South Africa. J S Afr Vet Assoc 83: 1

Lærke HN, Hedemann MS 2012: The digestive system of the pig. In: Bach Knudsen KE, Kjeldsen NJ, Poulsen HD, Jensen BB (Eds): Nutritional Physiology of Pigs. Online Publication, Videncenter for Svineproduktion

Lawrence BV, Anderson DB, Adeola O, Cline TR 1998: Changes in pars esophageal tissue appearance of the porcine stomach in response to transportation, feed deprivation, and diet composition. J Anim Sci 76: 788-795

Lawson GHK, McOrist S, Jasni S, Mackie RA 1993: Intracellular bacteria of porcine proliferative enteropathy: cultivation and maintenance in vitro. J Clin Microbiol 31: 1136-1142

Leiting R 2011: Common causes of sudden death in finishing pigs. National Hog Farmer, May 26, 2011. https://www.nationalhogfarmer.com/health-diseases/common-causes-of-sudden-death-pigs-0515

Loynachan AT, Nugent JM, Erdman MM, Harris DL 2004: Acute infection of swine by various Salmonella serovars. J Food Prot 67: 1484-1488

Maes D, Larriestra A, Deen J, Morrison R 2001: A retrospective study of mortality in grow-finish pigs in a multisite production system J Swine Health Prod 9: 267-273

Martineau GP, Le Morvan H, Decoux M 2008: Le Syndrome de Distension Intestinale Porcin (SDIP) (l'entérotoxémie). J Rech Porcine 40: 33-42

McOrist S, Barcellos DE, Wilson RJ 2003: Global patterns of porcine proliferative enteropathy. Pig Journal 51: $26-35$

McOrist S, Gebhart C 2006: Proliferative enteropathies. In: Straw BE, Zimmerman JJ, D Allaire S, Taylor DJ (Eds): Diseases of Swine. $9^{\text {th }}$ edn, Blackwell Publishing, $727 \mathrm{p}$.

Melnichouk SI 2002: Mortality associated with gastric ulceration in swine. Can Vet J 43: 223-225

Milner JA, Sellwood R 1994: Chemotactic response to mucin by Serpulina hyodysenteriae and other porcine spirochetes: potential role in intestinal colonization. Infect Immun 62: 4095-4099

Monteiro SDA 2011: Prevalence and risk factors for gastrics ulcers in swine. São Paulo, Brazil: Faculdade de Medicina da Universidade do Porto FMUP, 2011, from http://repositorio-aberto.up.pt/handle/10216/22219

Moreno Switt AI, Soyer Y, Warnick LD, Wiedmann M 2009: Emergence, distribution and molecular and phenotypic characteristics of Salmonella enterica serotype 4,5,12:I:-. Foodborne Pathog Dis 6: 407-415

Morin M, Sauvageau R, Phaneuf JB, Teuscher E, Beauregard M, Lagacé A 1984: Torsion of abdominal organs in sows: a report of 36 cases. Can Vet J 25: 440-442

Mushonga B, Yabaragiye B, Kandiwa E, Habarugira G, Samkange A 2017: A 3-year prospective study of the incidence of gastric ulcers in pigs slaughtered at Base Abattoir in Rwanda. Vet World 10: 873-879

Mushtaq M, Zubair S, Råsbäck T, Bongcam-Rudloff E, Jansson DS 2015: Brachyspira suanatina sp. nov., an enteropathogenic intestinal spirochaete isolated from pigs and mallards: genomic and phenotypic characteristics. BMC Microbiol 15: 208

Nielsen NO 1995: Rolled wheat as an aid to avoiding stomach problems in pigs. Pigs 10: 25-26

Novotný J, Reichel P, Kovačocyová K, Cigánková V, Almášiová V, Šipoš D 2016: Haemorrhagic bowel syndrome in fattening pigs. Acta Vet Beograd 66: 138-146

Omotosho OO, Emikpe BO, Lasisi OT, Jarikre TA 2016: Prevalence, distribution and pattern of gastric lesions in slaughtered pigs in South-Western Nigeria. Onderstepoort J Vet Res 83: 6

Parton A, Volk S, Weisse C 2006: Gastric ulceration subsequent to partial invagination of the stomach in a dog with gastric dilatation-volvulus. J Am Vet Med Assoc 228: 1895-1900

Pascua C, Costinara L, Merneaa I, Tătara D, Hermana V 2015: Prevalence of Lawsonia intracellularis infections in pig herds from the western Romania. Agric Agric Sci Procedia 6: 378-381

Pejsak, Z 2007: Krwotoczny zespół jelitowy u świń (in Polish, Haemorrhagic bowel syndrome in pigs). Zyc Wet 82: $398-400$

Popesko P, Hájovská B, Komárek V, Marvan F, Vrzgulová M 1992: Anatomy of livestock (in Slovak, Anatómia hospodárskych zvierat). Príroda Bratislava, 283

Prazeres C, Martins P, Raimundo R 2017: Prevalence of gastric lesion in pigs. Investigação 16: 50-55

Quintana-Hayashi MP, Mahu M, De Pauw N, Boyen F, Pasmans F, Martel A, Premaratne P, Fernandez HR, Teymournejad O, Teymournejad L, Maele LV, Haesebrouck F, Lindén SK 2015: The levels of Brachyspira hyodysenteriae binding to porcine colonic mucins differ between individuals, and binding is increased to mucins from infected pigs with de novo MUC5ac synthesis. Infect Immun 83: 4 1610-1619

Reed WM, Olander HJ, Thacker HL 1986: Studies on the pathogenesis of Salmonella typhimurium and Salmonella choleraesuis var kunzendorf infection in weanling pigs. Am J Vet Res 47: 75-83

Ruckebusch Y, Bueno L 1976: The effect of feeding on the motility of the stomach and small intestine in the pig. Br J Nutr 35: 397-405

Salyers AA, Abile-Cuevas CFA 1997: Why are antibiotic resistance genes so resistant to elimination? Antimicrob Agents Chemother 41: 2321-2325

Sarashina T, Taniyama H 1986: A case of Hyostrongylus rubidus infection in a pig. Nihon Juigaku Zasshi 48 : $163-167$ 
Schwartz KJ 2002: Hemorrhagic bowel syndrome (HBS): A diagnostic laboratory perspective. Proceedings of the $33^{\text {rd }}$ Annual Meeting of the American Association of Swine Veterinarians, Kansas City, pp. 405-408

Schwartz KJ 1991: Salmonellosis in swine. Compend Contin Educ Pract 13: 139-146

Stanton TB 2006: The genus Brachyspira. In: Dworkin M, Falkow S, Rosenberg E, Schleifer KH, Stackebrandt E (Eds): The Prokaryotes: Vol. 7: Proteobacteria: Delta and Epsilon Subclasses. Springer, New York, USA

Stege H, Jensen TK, Møller K, Baekbo P, Jorsal SE 2000: Prevalence of intestinal pathogens in Danish finishing pig herds. Prev Vet Med 46: 279-292

Straw B, Dewey C, Kober J, Henry SC 2002: Factors associated with death due to hemorrhagic bowel syndrome in two large commercial swine farms. J Swine Health Prod 10: 75-79

Straw B, Henry S, Nelssen J, Doster A, Moxley R, Rogers D, Webb D, Hogg A 1992: Prevalence of lesions in the pars esophagea of normal and sick pigs. Proc $12^{\text {th }}$ IPVS Cong, the Hague, the Netherlands, p. 386

Thomson JR, Miller WG, Woolfenden NJ, Thomson D 2007: Pressure-related abdominal changes in pigs with "whey bloat" - a case report. Pig J 59: 152-159

Thomson JR, Friendship M 2019: Digestive system, Intestinal torsion (volvulus) and hemorrhagic bowel syndromes In: Zimmerman JJ, Karriker LA, Ramirez A, Schwartz KJ, Stevenson GW, Zhang J (Eds): Diseases of Swine. $11^{\text {th }}$ edn. John Wiley \& Sons, Inc., Ames, IA, USA, 249-250

Turk JR, Fales WH, Maddox C, Miller M, Pace L, Fischer J, Kreeger J, Johnson G, Turnquist S, Ramos JA 1992: Pneumonia associated with Salmonella choleraesuis infection in swine: 99 cases (1987-1990). J Am Vet Med Assoc 201: 1615-1616

Uzzau S, Brown DJ, Wallis T, Rubino S, Leori G, Bernard S, Casadesús J, Platt DJ, Olsen JE 2000: Host adapted serotypes of Salmonella enterica. Epidemiol Infect 125: 229-255

Vannucci FA, Gebhart CJ 2014: Recent advances in understanding the pathogenesis of Lawsonia intracellularis infections. Vet Pathol 51: 465-477

Vannucci FA, Gebhart CJ, McOrist S 2019: Proliferative enteropathy. In: Zimmerman JJ, Karriker LA, Ramirez A, Schwartz KJ, Stevenson GW, Jianqiang Z (Eds): Diseases of Swine. $11^{\text {th }}$ edn. John Wiley \& Sons, Hoboken, NJ, USA, pp. 891-911

White M 2002: Twisted guts and stomach. https://www.nadis.org.uk/disease-a-z/pigs/twisted-guts-and-stomach/

Whittemore C 1998: The Science and Practice of Pig Production. Blackwell Science, Oxford, UK, pp. 537-549

Wilberts BL, Arruda PH, Kinyon JM, Madson DM, Frana TS, Burrough ER 2014: Comparison of lesion severity, distribution, and colonic mucin expression in pigs with acute swine dysentery following oral inoculation with "Brachyspira hampsonii" or Brachyspira hyodysenteriae. Vet Pathol 51: 1096-1108

Wilcock BP 1981: Salmonellosis. In: Leman AD, Straw B, Glock RD, et al. (Eds): Diseases of Swine, $6^{\text {th }}$ edn, Ames, Iowa State University Press, pp. 508-520

Wilcock BP, Schwartz K 1992: Salmonellosis. In: Leman AD, Straw BE, Mengeling WE, D’Allaire S and Taylor DJ (eds): Diseases of Swine, $7^{\text {th }}$ edn. Iowa State University Press, Ames, Iowa, pp. 570-583

Wondra KJ, Hancock JD, Behnke KC, Stark CR 1995: Effects of dietary buffers on growth performance, nutrient digestibility, and stomach morphology in finishing pigs. J Anim Sci 73: 414-420

Yoon H, Hong SK, Lee I, Yoo DS, Jung CHS, Lee E, Wee SH 2020: Clinical symptoms of African swine fever in domestic pig farms in the Republic of Korea, 2019. Transbound Emerg Dis 67: 2245-2248

Zhitnitskiy 2020: CVM 6969 LEC 001 Large Animal Medicine III (Twin Cities Fall 2020), Salmonella choleraesuis. https://open.lib.umn.edu/swinedisease/chapter/salmonella-choleraesuis/ 